\title{
The Royal College of Physicians and Surgeons of Glasgow: a Global Commitment to Surgical Education
}

\author{
Jaimin Bhatt ${ }^{1} \cdot$ Chandra Shekhar Biyani ${ }^{2,3} \cdot$ Abhay Rane $^{4,5} \cdot$ Michael McKirdy $^{5,6}$
}

Received: 8 January 2022 / Accepted: 15 January 2022/Published online: 24 January 2022

(c) Crown 2022

\begin{abstract}
The Royal College of Physicians and Surgeons of Glasgow is a community of health professionals working together to develop and improve patient care. The College is dedicated to supporting its members through education, training and continuing professional development. Furthermore, the College is committed to good global citizenship and has supported Fellows, Members and staff in their volunteering efforts.
\end{abstract}

Keywords Training $\cdot$ Technology $\cdot$ Education $\cdot$ Skills

\section{Introduction}

The Royal College of Physicians and Surgeons of Glasgow (RCPSG) was founded in 1599 by Maister Peter Lowe, who left his native Scotland for surgical training in France, where he remained for many years. He then returned to improve the medical standards of his local community. More than 400 years later, the RCPSG's vision remains "the highest possible standards of healthcare."

It pursues this vision through the provision of academic resources, examinations, educational activities, and

Chandra Shekhar Biyani

shekharbiyani@ hotmail.com

Jaimin Bhatt

Jaimin.Bhatt@ggc.scot.nhs.uk

Abhay Rane

Abhay.rane@ rcpsg.ac.uk

Michael McKirdy

Mike.McKirdy@rcpsg.ac.uk

1 Queen Elizabeth University Hospital, Glasgow, Scotland, UK

2 St. James's University Hospital, Leeds, UK

3 Co-Director Cadaveric Simulation Program, University of Leeds, Leeds, UK

4 East Surrey Hospital, Redhill, UK

5 The Royal College of Physicians and Surgeons of Glasgow, Glasgow, UK

6 NHS Greater Glasgow \& Clyde, Scotland, UK contributions to medical regulation and public policy. College membership encompasses surgeons, physicians, dentists, travel medicine specialists, and podiatrists with more than 15,000 Fellows and Members across Scotland, the United Kingdom (U.K.) and internationally. Having demonstrated in the sixteenth century that healthcare training and experience gained outside a local community can ultimately serve home populations, as well as build bridges abroad, the RCPSG continues to maintain and promote this perspective today.

\section{Current Vision}

In recent years, the idea of "global health" has come to capture the complexity of addressing global inequalities in health and their root causes. The most commonly used definition is as follows: "Global health is an area for study, research, and practice that places a priority on improving health and achieving equity in health for all people worldwide. Global health emphasises transnational health issues, determinants, and solutions; involves many disciplines within and beyond the health sciences and promotes interdisciplinary collaboration; and is a synthesis of populationbased prevention with individual-level clinical care" [1].

The publication of the first international development policy of the devolved Scottish administration in 2005 set out to promote "the positive contribution that Scotland can make to the world, and in particular to Low- and MiddleIncome Countries (LIMIC)" [2]. Our College is committed 
Table 1 Recommendations by Scottish Health Service

\begin{tabular}{ll}
\hline 1 & Developing a strategic approach \\
2 & Professionalising coordination and support \\
3 & Maximising benefits \\
4 & Ensuring effectiveness \\
5 & Valuing collaboration \\
6 & Expressing local commitment \\
7 & Defining support mechanism \\
8 & Setting expectation \\
\hline
\end{tabular}

to support the eight recommendations proposed by the Scottish Health Service Table 1.

The Scottish Government is focusing its resources towards four partner countries: Malawi, Zambia, Rwanda, and Pakistan. Thus far, Scotland's development efforts have particularly concentrated on Malawi, with whom strong historical links existed and with whom an inter-governmental cooperation agreement was signed in November 2005. College also has significant and long-standing ties with Malawi in context [3].

\section{The College of Surgeons of East, Central and Southern Africa}

COSECSA is a college without walls. It trains surgeons through an expanding network of 99 accredited hospitals and 165 accredited trainers in its 12-member countries. All trainees follow the same program of training for the first 2 years. They then are eligible to sit for COSECSA's membership exams. In the final 3 years, trainees choose one of seven specialties and then are eligible to take COSECSA's fellowship exams. The COSECSA training model is shorter than that of many comparable international surgical training institutions and is focused on clinical exposure. RCPSG is a key supporter of COSECSA and several of our surgeons have been making repeated visits to Malawi and Zambia to help with teaching and training.

\section{Medical Training Initiative}

The RCPSG supports the U.K. Department of Health's Medical Training Initiative (MTI), which offers a time-limited opportunity for postgraduate medical professionals, primarily from LMICs, to obtain training experience in the U.K. before returning to their country of origin. In addition to sourcing and coordinating placements for a range of applicants on a cost-recovery basis, the RCPSG has instituted its own MTI bursary scheme, the Livingstone Fellowship, which supports some of the start-up costs for Malawian trainee physicians or surgeons coming to the U.K. for targeted training.

\section{Professional Skills and Education}

Our fellows and members have a history of supporting underserved communities beyond their home environment. The College has delivered some of its standard educational courses in low-income environments, including Basic Surgical Skills courses.

RCPSG fellows and members from around the world can access a variety of travel bursaries, which aim to support the delivery of high-quality clinical input overseas and ensure the effective transfer of learning back into the home environment. RCPSG is part of the Healthcare Skills and Simulation Collaborative involves NHS Greater Glasgow and Clyde, NHS Education Scotland (NES), NHS Golden Jubilee, and NHS Lanarkshire. This partnership will open up opportunities for healthcare professionals including doctors in training, and those in more senior roles, to access world class clinical training in dedicated spaces that have been designed to mimic a real hospital environment. The simulation facilities based at our College have been kitted out with hospital beds and equipment, with anatomical models specially designed for teaching healthcare professionals.

Finally, RCPSG supports and/or participates in surgical examinations in India, Sri Lanka, Pakistan, and Malaysia.

\section{Technology-enhanced Learning}

The use of technology in medical education has been developing over many years. The COVID-19 pandemic has accelerated the uptake of newer technologies and platforms in every aspect of healthcare including education and training. Collaboration between academic staff, learning technologists, all forms of non-teaching staff and healthcare clinicians has allowed the College to develop and facilitate digital education programs (Fig. 1) (https://rcpsg.ac.uk/college/ covid-19/digital-education\#category=webinar). The portal supports training and education through webinars on clinical and non-clinical topic. Due to the high burnout rate in healthcare professionals, a particular consideration has been given to the Wellbeing on this portal [4].

RCPSG is proud of our historical links with all surgeons in India, and wish to strengthen these ties through ongoing dialogue and interaction. 


\section{Digital Education}

\section{(1) Providing certainty in uncertain times - Innovating our education delivery}

We are redesigning all of our courses and conferences to meet the changing needs of our members. Our approach means that you can still benefit from high-quality College CPD education with minimal risk to everyone attending or teaching the course. Read more here.

During these unprecedented times, we are faced with constant change and information overload. Our aim is to provide you with clear, factual information, backed up with supportive practical guidance covering both clinical situations and your own and your colleagues' wellbeing. Digital learning resources are being created with an understanding that we are all facing daily situations which are new to us, and we are under pressure.

\section{Q Search}

\section{Search...}

\section{T Filters}

\begin{tabular}{|l|l|l|l|l|l} 
Clinical topic Non-clinical learning & Webinars & Bite-sized learning & Wellbeing & Members only Available to all
\end{tabular}

\section{$\otimes$ Clear filters}
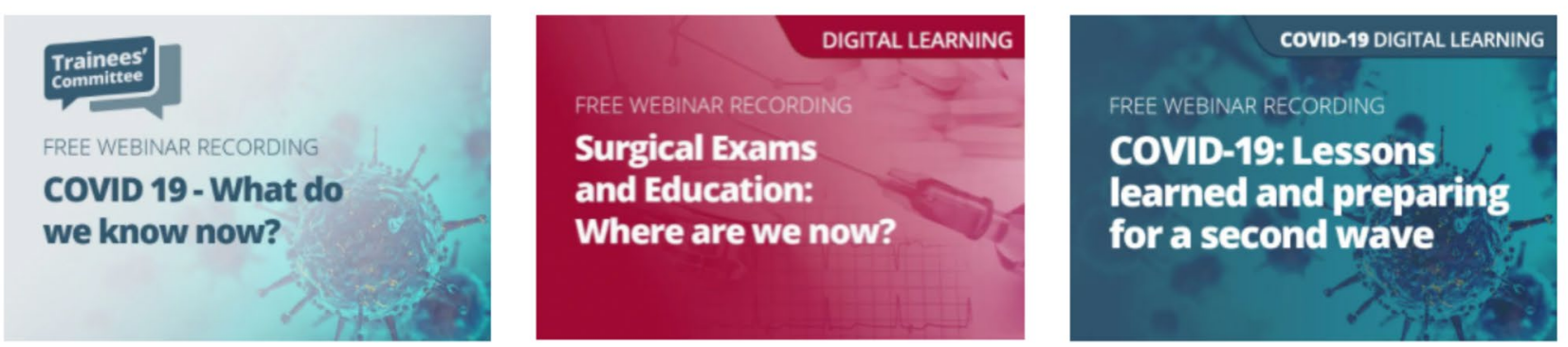

Fig. 1 Digital Education portal at the College Website

\section{References}

1. Koplan JP, Bond TC, Merson MH, Reddy KS, Rodriguez MH, Sewankambo NK et al (2009) Towards a common definition of global health. Lancet 373(9679):1993-1995

2. Scottish Executive (2005) Scottish Executive International Development Policy. March 2005. Accessed at http://www.gov. scot/Resource/Doc/37428/0024786.pdf on 18/11/16.

3. Scottish Government. Global Citizenship (2016) Scotland's International Development Strategy. Scottish Government. 2016.
Accessed at http://www.gov.scot/Publications/2016/12/4633 on $\underline{05 / 01 / 17}$

4. Digital Education https://rcpsg.ac.uk/college/covid-19/digitaleducation [Accessed on 18th December 2021]

Publisher's Note Springer Nature remains neutral with regard to jurisdictional claims in published maps and institutional affiliations. 